\title{
Selenium Uptake and Biotransformation and Effect of Selenium Exposure on the Essential and Trace Elements Status: Comparative Evaluation of Four Edible Plants
}

\author{
Oscar David Guevara Morenoํㅜ, Francisco Javier Acevedo Aguilar ${ }^{1}$, Eunice Yanez Barrientos*1 \\ ${ }^{1}$ Chemistry Department, University of Guanajuato, L. de Retana 5, 3600 Guanajuato, Mexico \\ *Corresponding author: phone +52 4737327555; e-mail: eybarrientos@ugto.mx
}

Received November 20"th, 2017 ; Accepted December $18^{\text {th }}, 2018$.

DOI: http://dx.doi.org/10.29356/jmcs.v62i2.388

\begin{abstract}
Due to the essential nature of selenium and the beneficial effects attributed to the consumption of selenized plants in human and animal health. The accumulation, metabolism in plants and the effects of this element on the nutritional quality of exposed crops is still a subject of study. The selenium plant enrichment, in addition to providing dietary supplements with organic selenium species as SeMet and MeSeCys, could be a strategy to yield functional foods that guarantee the recommended absorption of other essential minerals. To contributing to the design of biofortification/supplementation strategies to obtain selenized edible sprouts, in this work were selected four types of plants commonly consumed in Mexico (radish, alfalfa, sunflower and chard), which were exposed to different concentrations of sodium selenite $\left(0,0.25,0.5,1.0,5.0\right.$ and $10 \mathrm{mg}$ of Se $\left.\mathrm{L}^{-1}\right)$ for 10 days. At the end of the exposure time, the growth, uptake and biotransformation from iSe to oSe, as well as the impact of Se on the content of other essential elements were evaluated. The results obtained indicate that alfalfa could be a good candidate to produce selenized food supplement, due to its short germination time (5 days), high yield of biomass production without growth inhibition up to selenite concentration corresponding to $10 \mathrm{mg} \mathrm{L}^{-1}$. Using this exposure condition, tSe accumulated in biomass is high $\left(75.0 \mu \mathrm{g} \mathrm{g}^{-1}\right)$ with $66 \%$ of iSe transformed to oSe in plant and with enhanced uptake of important minerals, namely $\mathrm{Cu}, \mathrm{Mn}$, Mo, Ca and $\mathrm{K}$.
\end{abstract}

Key words: selenium; selenized dietary supplement; Se biotransformation in plants; biofortification.

Resumen. Debido a la naturaleza esencial del selenio y los efectos benéficos atribuidos al consumo de plantas selenizadas en la salud humana y animal. La acumulación, el metabolismo en las plantas y los efectos de este elemento en la calidad nutricional de los cultivos expuestos sigue siendo tema de estudio. El enriquecimiento de plantas con selenio, además de proporcionar suplementos dietéticos con especies orgánicas de selenio como SeMet y MeSeCys, también podría ser una estrategia para la producción alimentos funcionales que garanticen la absorción recomendada de otros minerales esenciales. Con el objetivo de contribuir en el diseño de estrategias de biofortificación/suplementación para obtener plantas comestibles seleinizadas, en este trabajo se seleccionaron cuatro tipos de plantas de consumo común en México (rábano, girasol, alfalfa y acelga), las cuales fueron expuestas a diferentes concentraciones de selenito de sodio $\left(0,0.25,0.5,1.0,5.0\right.$ y $10 \mathrm{mg}_{\text {de }}$ Se $\left.\mathrm{L}^{-1}\right)$ durante 10 días. Al término del periodo de exposición se evaluó el crecimiento, captación y biotransformación de selenio inorgánico (iSe) a Selenio orgánico (oSe), así como el impacto de Se sobre el contenido de otros elementos esenciales. Los resultados obtenidos indican que la alfalfa podría ser un buen candidato para la producción de suplemento alimenticio selenizado, debido a su corto tiempo de germinación (5 días), alto rendimiento de producción de biomasa

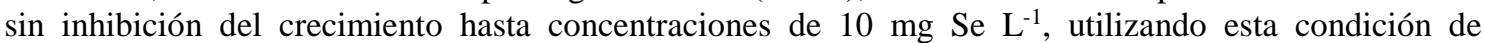
exposición, el selenio total acumulado en biomasa es alto $\left(75.0 \mu \mathrm{g} \mathrm{g}^{-1}\right)$ con un $66 \%$ de biotransformación, además de registrarse una mayor absorción de elementos esenciales como $\mathrm{Cu}$, Mn, Mo, Ca y K.

Palabras clave: selenio; suplementos alimenticios seleinizados; biotransformación de selenio en plantas; biofortificación. 


\section{Introduction}

The importance of selenium (Se) for human health and nutrition has long been recognized and related with its antioxidant and chemopreventive properties[1-3]. The Food and Nutrition Board of the Institute of Medicine (USA) set $55 \mu \mathrm{g}$ of Se day $^{-1}$ as a recommended dietary allowance (RDA) and $400 \mu \mathrm{g}$ of Se day ${ }^{-1}$ as a tolerable upper intake for adults. Although the human demand for Se is not high, the abundance of Se in the Earth's crust is low and not uniform. Thus, Se deficiency is recognized as a global health problem and is addressed by suitable supplementation [4]. In this regard, there is a clear preference for using dietary sources naturally rich in Se or products obtained via biofortification, as compared to the direct administration of selenium compounds [5]. Edible crops have often been enriched with Se and it is generally accepted that development of apposite phytotechnologies requires a thorough understanding of element uptake, translocation and assimilation processes at the molecular, physiological and agronomic levels. All these aspects are important because the bioavailability and utilization of selenium by living organisms are concentration- and species-dependent [6]. In plants, Se uptake and accumulation also depend on the biological species, stage of development and the physiological conditions [7]. Unrevealing ability for Se accumulation and biotransformation of inorganic forms (iSe) into organic species (oSe), such as methylselenocysteine (MeSeCys) or gamma-glutamyl-methylselenocysteine, is crucial while addressing the feasibility of the enriched plant in Se supplementation[8].

On the other hand, strong evidence exists that the traffic of some trace elements becomes affected by plant exposure to Se; selenium activity as an antagonist of heavy metals and selenium impact on the status of beneficial microelements have been reported [9]. Studies carried out for some species have shown that appropriate selenium fertilization causes not only the enhanced content of some trace elements but also is associated with the increased concentrations of important antioxidants such as phenolic compounds [10]. Therefore, selenium impact in plants has been evaluated in the context of better nutritional quality of foods derived from biofortified plants; beneficial effect of Se on plant growth and defense against environmental stress should also be noted in terms of more efficient production of crops and derived healthy food [11-14]. Due to the essential nature of selenium (in humans and animals) and the beneficial effects attributed to the consumption of selenized plants in human and animal health, Se accumulation and metabolism in plants as well as its effects on the nutritional quality of the exposed crops need to be clarified [15,16]. Plant enrichment with selenium, in addition of providing suitable Se dietary supplements, could also be a strategy for designing functional food ensuring the recommended uptake of other microelements or preventing from heavy metals toxicity[17-20].

In this work, the uptake and biotransformation of iSe to oSe by different plant species and the impact of Se on the content of other essential elements was evaluated, aiming to contribute in the design of biofortification strategies for plant-based supplementation. Four types of edible plants commonly consumed in Mexico were selected, under the criteria of short germination period, compatibility with hydroponic conditions, high biomass production and high nutritional value. The plants selected were: radish (Raphanus sativus l.), sunflower (Helianthus annuus), alfalfa (Medicago sativa) and chard (Beta vulgaris var. cicla). Selenium effects in these plants had previously been [21-27], except for chard. Raphanus sativus belongs to Brassicaceae - a family of plants cataloged as primary accumulators of selenium and capable of synthesizing low molecular mass methyl-seleno compounds; as for nutritional value, this plant presents relatively high content of glucosinolates, phenolic compounds, vitamins, phytochemicals with possible anticancer activity, anthocyanins and is a good source of elements such as, K, Ca and Mg [28,29]. Medicago sativa is one of the most cultivated forage plants in the world, it is characterized by protein content (2000-3000 kg/ha) about three times higher than soybean and 4 times higher than wheat; it is an important source of secondary metabolites such as saponins, flavonoids and phenolic compounds that are of considerable importance in the pharmaceutical industry and in agriculture. The third plant selected, alfalfa, is known for its tolerance to drought, heat and cold and for the remarkable efficiency of biomass production which is utilized as a high-quality fodder. Indeed, alfalfa hay contains about $16 \%$ of protein and $8 \%$ of mineral constituents in wet mass, it is also rich in vitamins A, E, D, and K. When grown as a coverage or as part of a crop rotation, alfalfa improves soil nutrient levels and decreases the need for synthetic fertilizers [30]. Formation of MeSeCys during in-vivo fortification has been reported [31]. Helianthus annuus, not only is edible plant for humans and animals, but due to the high content of essential oils, is used for biodisel production worldwide. It is a good source of secondary metabolites of biological activity such as terpenoids and flavonoids [32,33]. The feasibility of sunflower plant for phytoremediation has been studied focusing on soils and aquatic systems contaminated with Cd, Cr, Zn and Mn [32,33]. Finally, Beta vulgaris var. cycla is characterized by high content of vitamins A, C and B, bioelements such as Ca, 
Fe and P, fatty acids (palmitic, oleic, linoleic, linolenic), phospholipids, glycolipids, polysaccharides, ascorbic acid, folic acid, pectin, saponins, flavonoids, phenolic compounds and proline. Application of this plant extract has been suggested in the treatment of neurological disorders.

The results obtained in this work, in terms of total Se concentration, conversion of iSe to oSe and concentrations of major and minor mineral elements in the above four plants grown in the presence of Se(IV), encourage for further studies of alfalfa as a feasible dietary supplement of Se and some other bioelements.

\section{Experimental}

\section{Apparatus}

A model 7500ce ICP-MS (Agilent Technologies, Tokyo, Japan) with a Meinhard ${ }^{\circledR}$ nebulizer and Peltier cooled spray chamber $\left(2^{\circ} \mathrm{C}\right)$ was used for the determination of total selenium and other trace elements. An Agilent Technologies 4100 MP-AES nitrogen plasma atomic emission spectrometer controlled by Agilent MP Expert Software (actualized from MP-AES 4200) was used for determination of total concentrations of mayor elements. Agilent Series 1050 liquid chromatographic system controlled by using Chemstation (Agilent Technologies) coupled directly to inductively coupled plasma mass spectrometry detector was used for determination of selenium biotransformation.

\section{Reagents and samples}

Deionized water (18.2 M $\Omega$ cm, Labconco, USA) and HPLC-grade methanol (Fisher Scientific, Pittsburgh, USA) were used throughout. Sodium selenite, Hoagland solution reagents, selenomethionine (SeMet), Se-methyl-Se-cysteine (MeSeCys), Se-cystine (Se-Cys) 2, methanesulfonic acid, nitric acid, heptafluorobutyric acid (HFBA), $\beta$-mercaptoethanol and hydride peroxide were analytical reagent grade (Sigma-Aldrich).

External calibrations for selenium, trace and major elements were performed using an Agilent Technologies multi-elemental standard (1000 mg L-1 Fe, K, Ca, Na, Mg; $10 \mathrm{mg} \mathrm{L}^{-1} \mathrm{Ag}$, Al, As, Ba, Be, Cd, $\mathrm{Co}, \mathrm{Cr}, \mathrm{Mn}, \mathrm{Mo}, \mathrm{Ni}, \mathrm{Pb}, \mathrm{Sb}, \mathrm{Se}, \mathrm{Tl}, \mathrm{V}, \mathrm{Zn}, \mathrm{U}$ in $10 \% \mathrm{HNO}_{3}$ ), for ICP-MS, an Agilent Technologies mixed internal standard solution was also used $\left(2.0 \mathrm{mg} \mathrm{L}^{-1} \mathrm{In}, 10 \mathrm{mg} \mathrm{L}^{-1} \mathrm{Li}, 2.0 \mathrm{mg} \mathrm{L}^{-1} \mathrm{Y}, 2.0 \mathrm{mg} \mathrm{L}^{-1} \mathrm{Bi}, 5.0 \mathrm{mg}\right.$ $\mathrm{L}^{-1} \mathrm{Sc}$, and $2.0 \mathrm{mg} \mathrm{L}^{-1} \mathrm{Rh}$ ).

The analytical accuracy was demonstrated by analyzing two certified reference materials NIST 1643d (Trace elements in water) and NIST 1572 (Citrus Leaves).

\section{Plant growth}

Seeds of selected plants (Raphanus sativus l., Helianthus annus, Medicago sativa and Beta vulgaris var. cicla) were purchased in a garden specialized market. Before germination, seeds were sterilized in sodium hypochlorite $3.1 \% \mathrm{~m} / \mathrm{v}$ for $15 \mathrm{~min}$, then washed and soaked in deionized water for 30 min. Seed germination and plant exposure to selenium were performed in hydroponics using nutrient Hoagland solution of the following composition: $\mathrm{Ca}\left(\mathrm{NO}_{3}\right)_{2} 0.35 \mathrm{mM}, \mathrm{KNO}_{3} 0.255 \mathrm{mM}, \mathrm{MgCl}_{2} 0.91 \mathrm{mM}$, $\mathrm{KH}_{2} \mathrm{PO}_{4} 0.97 \mathrm{mM}, \mathrm{CaCl}_{2} 2.1 \mathrm{mM}, \mathrm{MoO}_{3} 23.13 \mu \mathrm{M}, \mathrm{MnCl}_{2} 3.9 \mu \mathrm{M}, \mathrm{Zn}\left(\mathrm{NO}_{3}\right)_{2} 0.37 \mu \mathrm{M}, \mathrm{Fe}\left(\mathrm{NO}_{3}\right)_{2} 10 \mu \mathrm{M}$, $\mathrm{CuSO}_{4} 0.44 \mu \mathrm{M}$ and $\mathrm{H}_{3} \mathrm{BO}_{3} 32.13 \mu \mathrm{M}, \mathrm{pH}$ 5.8. The periods of complete germination for each plant were different: 15 days for radish, 5 days for alfalfa, 10 days for sunflower and 15 days for chard. Sprouts were exposed to different concentrations of sodium selenite $\left(0,0.25,0.5,1.0,5.0\right.$, and $\left.10 \mathrm{mg} \mathrm{Se} \mathrm{L}^{-1}\right)$ for 10 days. At the end of exposure biomass harvested for each culture was weighed, washed with deionized water, ground in liquid nitrogen and freeze-dried.

\section{ICP-MS determination of total selenium and trace elements.}

$30 \mathrm{mg}$ of each freeze-dried sample were digested with $500 \mu \mathrm{l}$ concentrated nitric acid, $250 \mu \mathrm{l}$ of internal standard solution (2.0 $\mu \mathrm{g} \mathrm{L}^{-1}$ each In, Y, Bi, Rh; $5.0 \mu \mathrm{g} \mathrm{L}^{-1}$ of Sc and $10 \mu \mathrm{g} \mathrm{L}{ }^{-1}$ of Li) and $500 \mu \mathrm{L}$ of hydrogen peroxide. Volume of the digested samples was adjusted to $2.0 \mathrm{~mL}$ with deionized water. Samples were centrifuged and $250 \mu \mathrm{L}$ aliquot was diluted to $5.0 \mathrm{~mL}$ with deionized water and introduced to ICP-MS system. The instrument operation conditions were as follows: forward power, $1500 \mathrm{~W}$; plasma gas flow rate, $15 \mathrm{~L} \mathrm{~min}^{-1}$; carrier gas flow rate, $0.89 \mathrm{~L} \mathrm{~min}^{-1}$; make-up gas flow rate, $0.15 \mathrm{~L} \mathrm{~min}^{-1}$; sampling depth, $10 \mathrm{~mm}$; dwell time, $100 \mathrm{~ms}$ per isotope; platinum sampling and skimmer cones were used. Octapole collision/reaction cell was pressurized with $\mathrm{He}, 4.0 \mathrm{~mL} \mathrm{~min}{ }^{-1}$. The isotopes ${ }^{55} \mathrm{Mn},{ }^{63} \mathrm{Cu},{ }^{68} \mathrm{Zn},{ }^{78} \mathrm{Se},{ }^{82} \mathrm{Se}$, ${ }^{95} \mathrm{Mo},{ }^{115} \mathrm{In},{ }^{7} \mathrm{Li},{ }^{89} \mathrm{Y},{ }^{209} \mathrm{Bi},{ }^{45} \mathrm{Sc},{ }^{103} \mathrm{Rh}$ were monitored and analyte signals standardized to IS. 
Seven-point external calibration was performed covering the concentration range 0 - $100 \mu g \mathrm{~L}^{-1}$ for each element, in the presence of multi-element internal standard solution $\left(10 \mu \mathrm{L} \mathrm{L}^{-1}\right.$ each In, Y, Rh, Bi; $25 \mu \mathrm{g} \mathrm{L}^{-1}$ of Sc and $50 \mu \mathrm{g} \mathrm{L}^{-1}$ of Li). The instrumental detection limits were $51 \mathrm{ng} \mathrm{L}^{-1}$ for $\mathrm{Cu}, 4.9 \mathrm{ng} \mathrm{L^{-1 }}$ for Mn, $156 \mathrm{ng} \mathrm{L}^{-1}$ for Zn, $9.8 \mathrm{ng} \mathrm{\textrm {L } ^ { - 1 }}$ for Mo, $170 \mathrm{ng} \mathrm{L}^{-1}$ for Ni and $205 \mathrm{ng} \mathrm{L}^{-1}$ for Se. Element concentrations found in the analysis of NIST 1572 Citrus Leaves reference material were: $16.9 \pm 0.6 \mu \mathrm{g} \mathrm{g}$ f $^{-1}$ for Cu, $21.9 \pm$ $1.7 \mu \mathrm{g} \mathrm{g}^{-1}$ for Mn, $32.2 \pm 1.3 \mu \mathrm{g} \mathrm{g}^{-1}$ for $\mathrm{Zn}, 0.30 \pm 0.1 \mu \mathrm{g} \mathrm{g}^{-1}$ for Mo and $0.24 \pm 0.2 \mu \mathrm{g} \mathrm{g}^{-1}$ for $\mathrm{Ni}$, all of them in agreement with the certified values $\left(16.5 \pm 1.0 \mu \mathrm{g} \mathrm{g}^{-1}\right.$ for $\mathrm{Cu}, 23.0 \pm 2.0 \mu \mathrm{g} \mathrm{g}^{-1}$ for $\mathrm{Mn}, 29.0 \pm 2.0 \mu \mathrm{g} \mathrm{g}^{-1}$ for $\mathrm{Zn}, 0.17 \pm 0.09 \mu \mathrm{g} \mathrm{g}^{-1}$ for Mo, and $0.6 \pm 0.3 \mu \mathrm{g} \mathrm{g}^{-1}$ for Ni). For total element determination in NIST 1643d Trace Elements in water, the concentrations found were: $21.3 \pm 2.1 \mu \mathrm{g} \mathrm{L}^{-1}$ for $\mathrm{Cu}, 38.0 \pm 0.6 \mu \mathrm{g} \mathrm{L}^{-1}$ for $\mathrm{Mn}, 73.6 \pm 1.8 \mu \mathrm{g} \mathrm{L} \mathrm{L}^{-1}$ for $\mathrm{Zn}, 59.8 \pm 1.6 \mu \mathrm{g} \mathrm{L} \mathrm{L}^{-1}$ for Ni, $113 \pm 0.15 \mu \mathrm{g} \mathrm{L}^{-1}$ for Mo and $11.1 \pm 0.5 \mu \mathrm{g} \mathrm{L}{ }^{-1}$ for Se, also in agreement with the certified values $\left(20.5 \pm 3.8 \mu \mathrm{g} \mathrm{L}^{-1}\right.$ for $\mathrm{Cu}, 37.7 \pm 0.8 \mu \mathrm{g} \mathrm{L} \mathrm{L}^{-1}$ for $\mathrm{Mn}, 72.5$ $\pm 0.7 \mu \mathrm{g} \mathrm{L}{ }^{-1}$ for $\mathrm{Zn}, 58.1 \pm 2.7 \mu \mathrm{g} \mathrm{L}^{-1}$ for $\mathrm{Ni}, 112.9 \pm 1.7 \mu \mathrm{g} \mathrm{L^{-1 }}$ for Mo and $11.4 \pm 0.2 \mu g \mathrm{~L}^{-1}$ for Se respectively). All analyses were run in triplicate.

\section{MP-AES determination of total mayor elements}

Similar as for ICP-MS, three aliquots per sample were digested, yet taking $30 \mathrm{mg}$ aliquots of freeze-dried biomass and adding $1 \mathrm{~mL}$ of concentrated nitric acid. The samples were heated al $80{ }^{\circ} \mathrm{C}$ for 10 min followed by $120^{\circ} \mathrm{C}$ for $3 \mathrm{~h}$. After centrifuged, $0.5 \mathrm{~mL}$ were withdrawn and diluted to $3 \mathrm{~mL}$ with deionized water. The instrument operation conditions were as follows: Nitrogen pressure 140 psi, integration time $3 \mathrm{~s}$, One Nebulizer ${ }^{\circledR}$ and Cyclonic one step spray chamber were used. The wavelengths $445.478 \mathrm{~nm}$ for Ca, 279.553nm for Mg, $259.940 \mathrm{~nm}$ for Fe, $589.592 \mathrm{~nm}$ for Na and $769.897 \mathrm{~nm}$ for K were monitored. Different nebulizer pressure and viewing position values were used for each wavelength (80 $\mathrm{kPa}$ and -10 for $\mathrm{Ca}, 240 \mathrm{kPa}$ and 0 for $\mathrm{Mg}, 240 \mathrm{kPa}$ and -30 for Fe, $100 \mathrm{kPa}$ and -10 for Na and $240 \mathrm{kPa}$ and -10 for K). The instrumental detection limits were: $10.1 \mu \mathrm{g} \mathrm{L} \mathrm{L}^{-1}$ for $\mathrm{Ca}, 7.8 \mu \mathrm{g} \mathrm{L}{ }^{-1}$ for Na, $3.5 \mu \mathrm{g} \mathrm{L}{ }^{-1}$ for $\mathrm{Mg}, 12.5 \mu \mathrm{g} \mathrm{L}{ }^{-1}$ for Fe and $6.7 \mu \mathrm{g} \mathrm{L}{ }^{-1}$ for $\mathrm{K}$. In the analysis of the certified reference material NIST 1572 (Citrus leaves), the following concentrations were found: $3.02 \pm 0.12 \%$ for $\mathrm{Ca}, 1.86 \pm 0.01 \%$ for K, 0.57 $\pm 0.01 \%$ for $\mathrm{Mg}, 89.4 \pm 1.5 \mathrm{mg} \mathrm{L}^{-1}$ for $\mathrm{Fe}$ and $162 \pm 3$ for $\mathrm{Na}$, in agreement with certified values (3.15 \pm $0.10 \%$ for Ca, $1.82 \pm 0.06 \%$ for K, $0.58 \pm 0.03 \%$ for Mg, $90 \pm 10 \mathrm{mg} \mathrm{L}^{-1}$ for Fe and $160 \pm 3$ for Na, respectively). All analyses were run in triplicate.

\section{Evaluation of Se(IV) biotransformation to organic Se in plants}

To $100 \mathrm{mg}$ aliquot of the biomass, $2.0 \mathrm{~mL}$ of methanesulfonic acid $4.0 \mathrm{~mol} \mathrm{~L}{ }^{-1}$ were added and the mixture was heated at reflux during $16 \mathrm{~h}\left(120^{\circ} \mathrm{C}\right)$. The obtained hydrolysate was evaporated, and the residue was resuspended in $10 \mathrm{~mL}$ of HFBA $0.1 \% \mathrm{~m} / \mathrm{v}$ for ICP-MS. For each sample, hydrolysis was carried out in triplicate. It is noteworthy that methanesulfonic acid hydrolysis was selected due to the efficient release of Se- methionine from proteins, as demonstrated elsewhere [34]. Liquid chromatography separation was achieved on a reversed phase Polaris C18 column using isocratic elution with HFBA 0.1\%: methanol (95:5) at the flow rate of $1.0 \mathrm{~mL} \mathrm{~min}^{-1}$; the injection volume was $20 \mu$ l. Column effluent was online introduced to ICP-MS system for Se detection and quantification. Instrument operation conditions were the same as described for total element determination. The isotopes ${ }^{78} \mathrm{Se}$ and ${ }^{82} \mathrm{Se}$ were monitored. Assignation of the chromatographic peaks was based on the retention times as compared to the standards: Se(IV), Se Met, SeMeSeCys and (SeCys)2. Independent calibration was carried out using Se(IV) standard at concentration $0-10 \mu \mathrm{g}$ Se $\mathrm{L}^{-1}$. Conversion of iSe to oSe was calculated as the percentage of Se content in the elution region from 0.85 min to 6.0 min with respect to total Se eluted from the column.

\section{Statistical analysis}

Descriptive statistics was performed to obtain means and standard deviation. Student's t test was carried out to compare differences in growth between plants exposed to Se and controls, significance was accepted for $p$ values $<0.05$. Statistics 6.0 (StatSoft, USA) software was used.

To identified differences among the Se fortification conditions, Tukey's HSD test was performed $(\mathrm{p}<0.05)$ using the values obtained of the ratio between total Se found in biomass and Se(IV) in medium. To observe possible relationships between parameters. Principal Components Analysis (PCA) were performed (Unscrambler 7.5, Camo, Norway). 


\section{Results and Discussion}

\section{Evaluation of selenium effect on the plant growth}

The growth of four plant types was different even without Se(IV) exposure; germination was completed in 5 days for alfalfa and in 10 days for sunflower whereas radish and chard needed 15 days to finish this stage of growth. Once germinated, each plant was exposed to Se(IV) for 10 days; in Fig. 1, the amounts of fresh biomass obtained for each plant growing in the presence of different Se(IV) concentrations, are presented. In same graph (Fig. 1) treatments with significant differences ( $\mathrm{p}$ values $<$ 0.05 ) respect to control were tagged with an asterisk. For Medicago sativa (alfalfa), slight beneficial effect on the growth was observed at low Se (IV) concentration $\left(0.25 \mathrm{mg} \mathrm{L}^{-1}\right)$, as reported previously for other species such as L. sativum [9]. For higher Se(IV) concentrations, biomass production was practically not affected by selenium and was comparable to the controls. Of note, this plant presented better growth with respect to radish and chard. For Raphanus sativus (radish), the exposed plants showed similar growth as controls up to Se(IV) concentration in medium $1.0 \mathrm{mg} \mathrm{L}^{-1}$ whereas for more harsh exposure conditions (5.0 and $10 \mathrm{mg} \mathrm{L}^{-1}$ of Se(IV) in medium), growth was clearly inhibited. The growth of Helianthus annuus was inhibited in Se concentration-dependent manner, starting from the lowest Se(IV) concentration in medium. For Beta vulgaris (chard), the lowest amount of biomass was obtained, and its growth was inhibited by Se(IV) in similar way as observed for sunflower. Nevertheless, it should be stressed that adverse effects as chlorosis, malformed tissue or plant death were not observed for any of four plants.

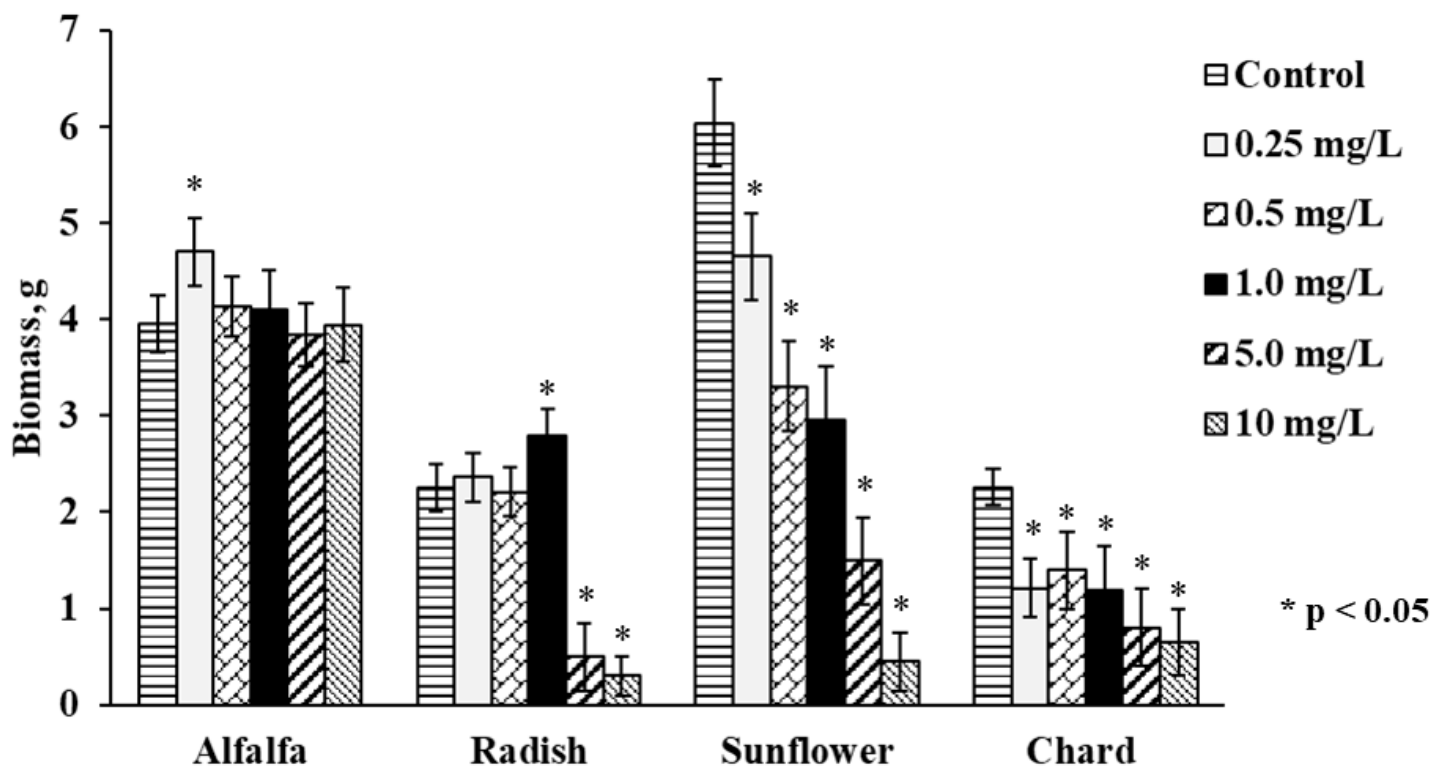

Fig. 1. Plants biomass obtained under different exposure conditions to Se(IV).

To facilitate comparative evaluation of four plants as potential candidates for Se supplementation, the most representative results of this work are summarized in Table 1. Accordingly, alfalfa seems to be a good choice in terms of germination time and ability to grow in the presence of relatively high Se(IV) concentrations. 
Table 1. Comparative evaluation of four plant types in terms of Se(IV) impact on their growth, Se uptake, iSe biotransformation to oSe and on the concentration of some mineral elements. Data presented are based on the results obtained for plants exposed to different concentration of sodium selenite for 10 days.

\begin{tabular}{|c|c|c|c|c|}
\hline & Radish & Alfalfa & Sunflower & Chard \\
\hline Germination completed & 15 days & 5 days & 10 days & 15 days \\
\hline $\begin{array}{l}\text { Maximum Se concentration in } \\
\text { medium without growth inhibition }\end{array}$ & $1.0 \mathrm{mg} \mathrm{L}^{-1}$ & $10 \mathrm{mg} \mathrm{L}^{-1}$ & $0.25 \mathrm{mg} \mathrm{L}^{-1}$ & $0.25 \mathrm{mg} \mathrm{L}^{-1}$ \\
\hline $\begin{array}{l}\text { Suitable Se concentration in } \\
\text { medium }\end{array}$ & $0.25-1.0 \mathrm{mg} \mathrm{L}^{-1}$ & $0.25-1.0 \mathrm{mg} \mathrm{L}^{-1}$ & $0.25 \mathrm{mg} \mathrm{L}^{-1}$ & $0.25 \mathrm{mg} \mathrm{L}^{-1}$ \\
\hline Total Se in biomass ${ }^{2}$ & $19.5-68.2 \mu g^{-1}$ & $20.7-75.0 \mu g^{-1}$ & $35.1 \mu \mathrm{g} \mathrm{g}^{-1}$ & $6.25 \mu \mathrm{g} \mathrm{g}^{-1}$ \\
\hline $\begin{array}{l}\text { Most } \quad \text { efficient } \\
\text { biotransformation } \\
\text { obtained for (Se(IV) in medium) }\end{array}$ & $\begin{array}{l}81 \% \\
\left(1 \mathrm{mg} \mathrm{L} \mathrm{L}^{-1}\right)\end{array}$ & $\begin{array}{l}76 \% \\
\left(1 \mathrm{mg} \mathrm{L}^{-1}\right)\end{array}$ & $\begin{array}{l}48 \% \\
\left(0.25 \mathrm{mg} \mathrm{L}^{-1}\right)\end{array}$ & $\begin{array}{l}45 \% \\
\left(10 \mathrm{mg} \mathrm{L}^{-1}\right)\end{array}$ \\
\hline Minoritary elements up-regulated ${ }^{3}$ & Mo & $\mathrm{Cu}, \mathrm{Mn}, \mathrm{Mo}$ & $\mathrm{Mn}$ & Zn, Ni \\
\hline Major elements up-regulated ${ }^{4}$ & $\mathrm{Na}, \mathrm{Mg}$ & $\mathrm{Ca}, \mathrm{K}$, & $\mathrm{Ca}, \mathrm{K}, \mathrm{Na}$ & $\mathrm{Fe}$ \\
\hline
\end{tabular}

\section{Total selenium in biomass under different exposure conditions}

The detailed results obtained by ICP-MS analysis of acid digested plants are presented in Table $1 \mathrm{~S}$ in the electronic supplementary material (SM). As could be expected, selenium concentration in plants was increasing accordingly with the increasing concentration of Se(IV) in medium. Considering data

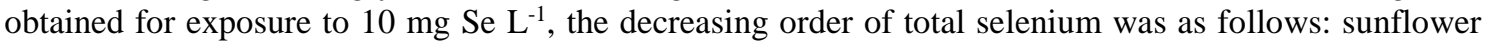
$\left(239 \mu \mathrm{g} \mathrm{g}^{-1}\right)>$ alfalfa $\left(215 \mu \mathrm{g} \mathrm{g}^{-1}\right)>$ radish $\left(203 \mu \mathrm{g} \mathrm{g}^{-1}\right)>$ chard $\left(108 \mu \mathrm{g} \mathrm{g}^{-1}\right)$. To evaluate Se fortification in all plants for all exposure conditions, a ratio between total Se found in biomass and Se(IV) in medium was calculated and the results obtained are shown in Fig. 2. For each plant species, this ratio tended to decrease with increasing selenite concentration in medium; however, for alfalfa and radish, relatively high uptake

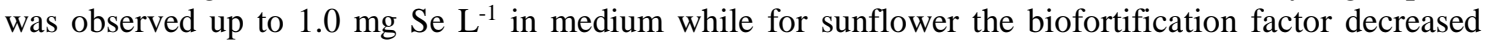
starting from $0.5 \mathrm{mg} \mathrm{Se}^{-1}$ in medium. The poorest Se uptake was observed for chard although total selenium (tSe) in this plant was not strongly affected by the exposure conditions. For each plant, the concentration range of Se(IV) in medium providing the best possible Se uptake, is presented in Table 1. As already mentioned, alfalfa and radish were two plants with relatively high Se uptake among four species studied. 


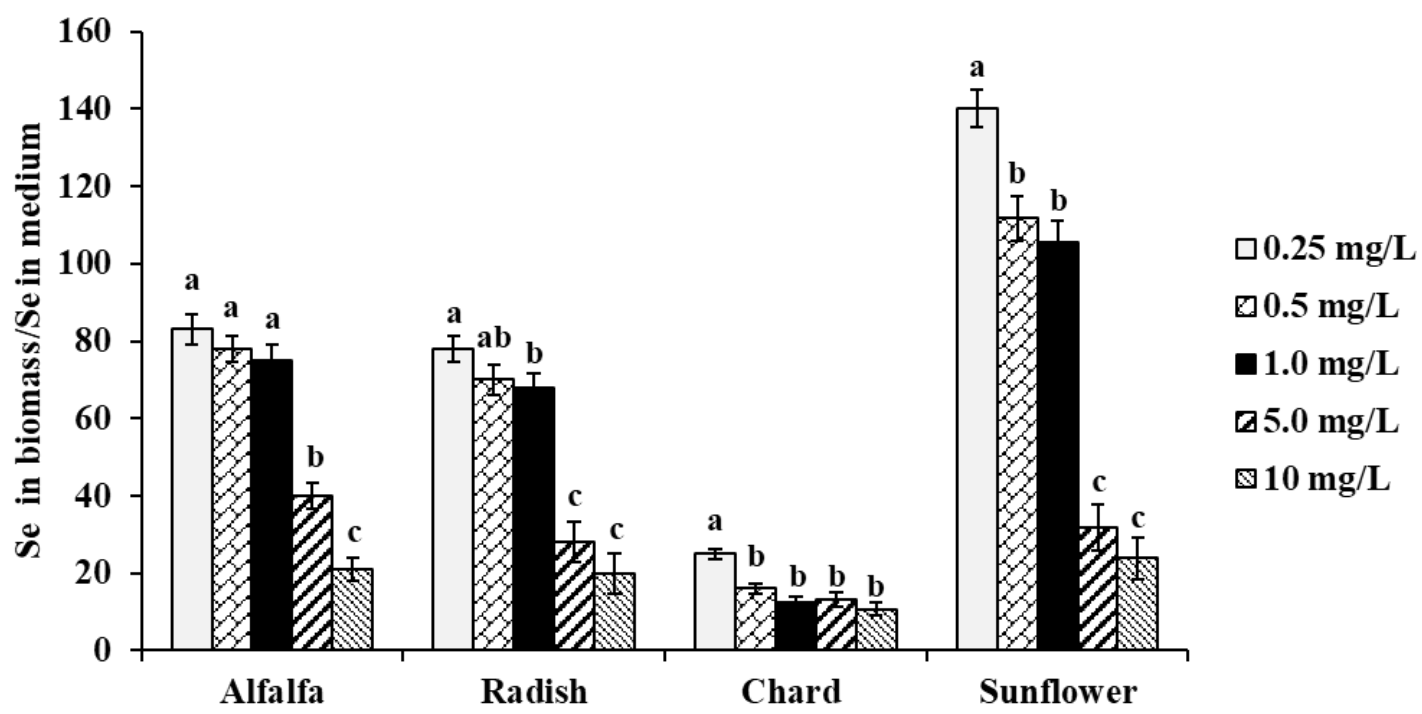

Fig. 2. Effect of Se(IV) concentration in medium on Se uptake by different plants, evaluated as the ratio of tSe in biomass to Se in the growth medium.

\section{Effect of Se(IV) exposure on the concentrations of minor and major mineral elements in plants - principal component analysis}

With the purpose of finding the most feasible candidate plant and the best conditions of Se(IV) treatment in terms of the increased uptake of other potentially beneficial elements, $\mathrm{Mn}, \mathrm{Cu}, \mathrm{Zn}$ and Mo were determined in acid digested biomass of plants by ICP-MS (detailed results presented in Table 1S, $\mathrm{SM}$ ). Furthermore, major essential elements ( $\mathrm{Ca}, \mathrm{Na}, \mathrm{K}, \mathrm{Fe}$ and $\mathrm{Mg}$ ) were determined by MP-AES and the obtained concentrations are listed in Table 2S (SM). Even though some differences of elements concentrations among plants and Se(IV) concentration in medium could be easily perceived, the direct interpretation of these results is not straightforward due to relatively high data dimensionality: four plants, five exposure conditions, ten elements determined. To detect possible relationships between exposure conditions and elements concentrations for different plants, principal component analysis (PCA) was carried out. This multivariate method is a common tool used to observe data structure in a space of reduced dimensionality of few (two or three) principal components.

In the first approach, PCA was performed taking concentrations of Se, $\mathrm{Zn}, \mathrm{Mn}, \mathrm{Cu}, \mathrm{Mo}$, Ni Ca, $\mathrm{Mg}, \mathrm{Na}, \mathrm{Fe}$ and $\mathrm{K}$ found in the biomass for all exposure conditions (Se(IV) concentration in medium) and in all four plants. As shown in Fig 1S (SM), the first two components accounted for $72 \%$ of the total data variability; this model spotted differences between plant species (four clusters on the scores plot, Fig. 1Sa, $\mathrm{SM}$ ) but did not enable to detect any relationships among variables (X-loading plot, Fig. 1bS, SM). It was decided then to perform PCA individually, for each plant. As an example, a model obtained for alfalfa is presented in Fig. 3; statistical significance relied on $90 \%$ of data variability described by two first principal components. The distribution of samples (scores plot, Fig. 3a) was according to the exposure conditions: the control sample and those obtained for low concentrations of selenium treatments $(0.25$ and $0.5 \mathrm{mg} \mathrm{L}$ ${ }^{1}$ ) are located at positive values of the first component (on the right) whereas the samples obtained for high concentration of selenium (1.0, 5.0 and $10 \mathrm{mg} \mathrm{L}^{-1}$ ) are located at negative values of first component (on the left). In the two-dimensional X-loading plot presented in Fig. 3b, variables corresponding to K, Ca, Mn, $\mathrm{Cu}$ and Mo form a cluster with Se and are located in the space corresponding to the high Se treatment, indicating that exposure to Se(IV) caused increased uptake of these elements in alfalfa. More specifically, relating distribution of samples with location of variables (Fig. 3a and Fig. 3b), Se(IV) concentration in

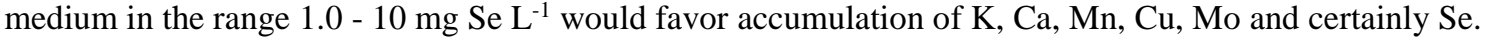
PCA models obtained for other plants are presented in supplementary material (Fig. 2S for sunflower, Fig. 3S for radish and Fig. 4S for chard); the results were less significant (the first two PCs accounted for less than $80 \%$ of variance) and clustering of variables was less marked as compared to alfalfa. For each plant, the elements found at higher concentrations under exposure to Se(IV) are listed in Table 1. Overall, the best ability of Se(IV) to regulate trace mineral content was observed for alfalfa; with the increasing concentrations of selenium in medium, enhanced uptake of $\mathrm{Cu}, \mathrm{Mn}, \mathrm{Mo}, \mathrm{Ca}$ and $\mathrm{K}$ was detected. For 
radish, the uptake of Mo, Na and Mg was favored; for sunflower, the affected elements were Mn, Ca, K, $\mathrm{Na}$ and for chard these were: $\mathrm{Zn}, \mathrm{Ni}, \mathrm{Fe}$. The obtained results are relevant and might be helpful in the design of dietary trace element supplements. Noteworthy, improving the uptake of $\mathrm{K}, \mathrm{Mg}$ and $\mathrm{Ca}$ has been addressed in several biofortification studies mainly due to the high dietary demand in humans and common deficiencies in consumption [35]. The application of element-containing fertilizers has been reported as problematic because of the problems associated with the transport through phloem of some of these elements as Ca [36,37]. On the other hand, an important beneficial effect of Se fortification was observed, $\mathrm{Ni}$ levels found in biomass decreased when plants were exposed to selenium. This protective effect of selenium against the uptake and toxicity of heavy metals has been described for several plant species $[9,38,39]$. Based on the results of this work, exposure of alfalfa to $1.0 \mathrm{mg} \mathrm{Se} \mathrm{L}^{-1}$ in form of Se(IV) seems to be a good start for elaboration of natural dietary supplement; however, plant capacity to synthesize oSe should also be considered.

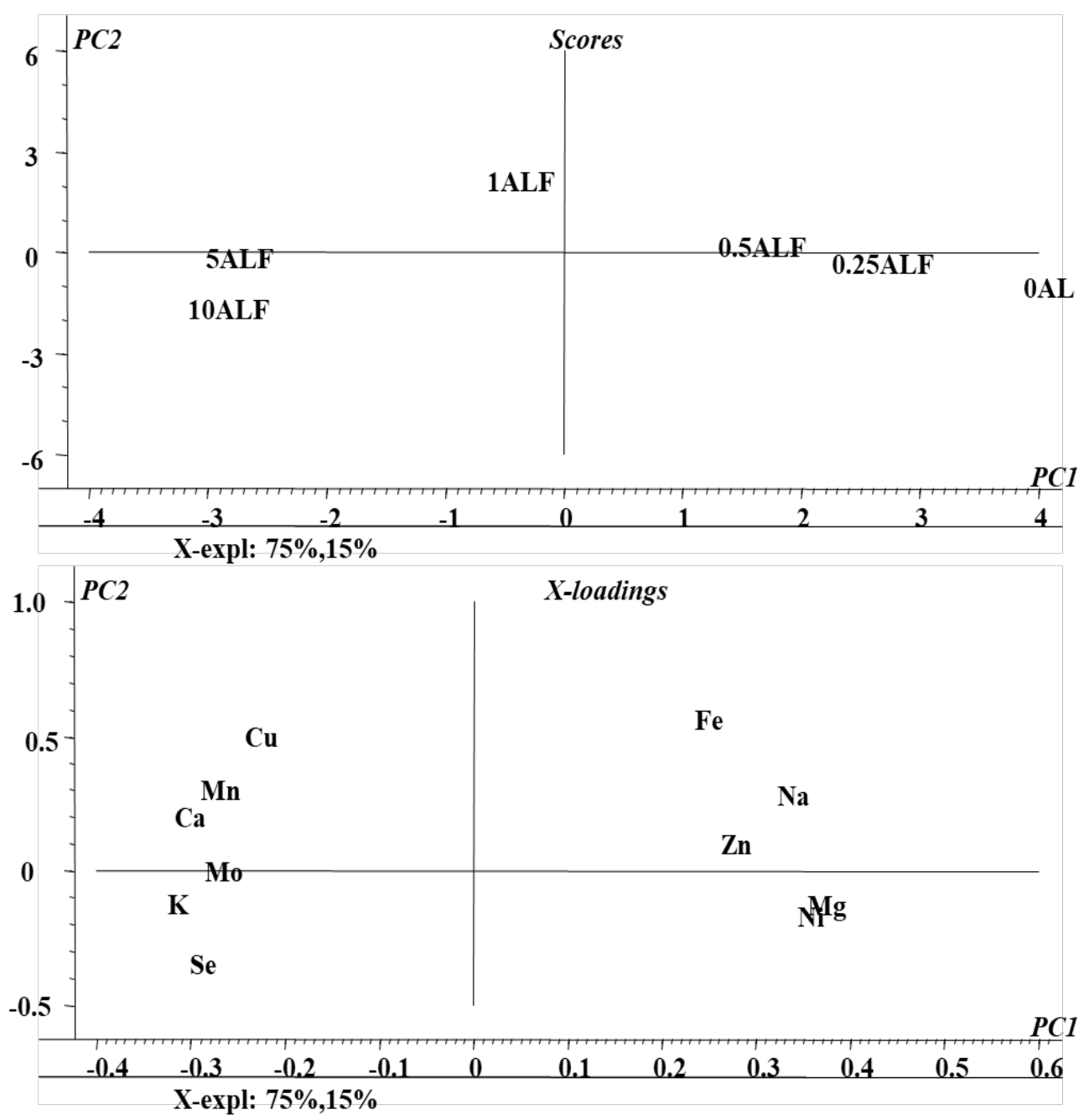

Fig. 3. Principal components analysis (PCA) of elements concentrations found in biomass of Alfalfa under different conditions of exposure to Se(IV): a) Two-dimensional plot of the sample scores and b) Twodimensional plot of variable loadings in the space defined by the first two principal components.

\section{Evaluation of selenium biotransformation}

Selenium speciation in Se-enriched organisms has been extensively studied [8]. As indicated in introduction, MeSeCys, SeMet, gamma-glutamyl-methylselenocysteine are the main organic species reported in selenized plants [8,38]. Specifically, for radish SeMet, MeSeCys, (SeCys) 2 were reported [21,22], for alfalfa SeMet, MeSeCys [39,40] and for sunflower SeMet [41], speciation analysis for chard have not been performed. On the other part, it is widely accepted that oSe contained in natural products is 
a better source for selenium supplementation as compared to iSe. That is why the objective of this work was to evaluate biotransformation of iSe to oSe by each of the selected plant rather than to carry out the detailed characterization of individual Se species. Analysis was carried out for plants exposed to 0.25, 1.0 and $10 \mathrm{mgSe} \mathrm{L}^{-1}$, previously selected under criterions of plant growth and Se uptake (Table 1); biomass samples were hydrolyzed with methanesulfonic acid to ensure the presence of small Se-compounds feasible to be separated by reversed phase column. A typical HPLC-ICP-MS system was applied and in Fig. 4a, a chromatogram obtained for the mix of Se standards $\left(10 \mu \mathrm{gSe} \mathrm{L}^{-1}\right.$ each), is presented. Based on the retention times obtained for individual compounds $(49.0 \pm 2.1 \mathrm{~s}$ for iSe, $102 \pm 2.4 \mathrm{~s}$ for (SeCys) $2,133 \pm 2.3 \mathrm{~s}$ for MeSeCys and $303 \pm 2.6$ s for SeMet) the elution region 0-70 s was assigned to iSe while the fractions eluted later were considered as oSe. In Fig. 4b, two chromatograms are shown that were obtained for the non-

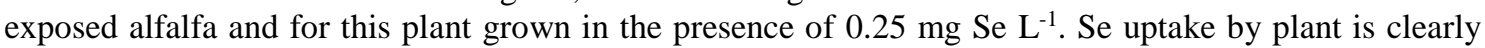
observed as well as the partial conversion of iSe (which was added to the growth medium) to oSe. In addition to SeMet, several other oSe species were detected yet their identification was out of the scope of this work. The percentage of Se conversion was calculated by dividing area of chromatogram for oSe by total area of chromatogram (70 - 360s) and the obtained results are presented in Fig. 5 (percentage values provided in Table 3S, SM). The most efficient iSe conversion was observed for radish and alfalfa under exposure to $1.0 \mathrm{mg} \mathrm{Se} \mathrm{L}^{-1}$ (81\% and 76\%, respectively) whereas for other two plants conversion percentages were lower than $50 \%$ under any exposure condition. It is also important that alfalfa grown in the presence of $10 \mathrm{mg} \mathrm{Se} \mathrm{L}^{-1}$ was capable to biotransform $66 \%$ of iSe to organic species, which is another characteristic making this plant attractive in terms of Se supplementation. Indeed, data presented in Table 1 point out that alfalfa might the most feasible plant among four species studied in this work and future research would be focused on the refining the biofortification procedure. 

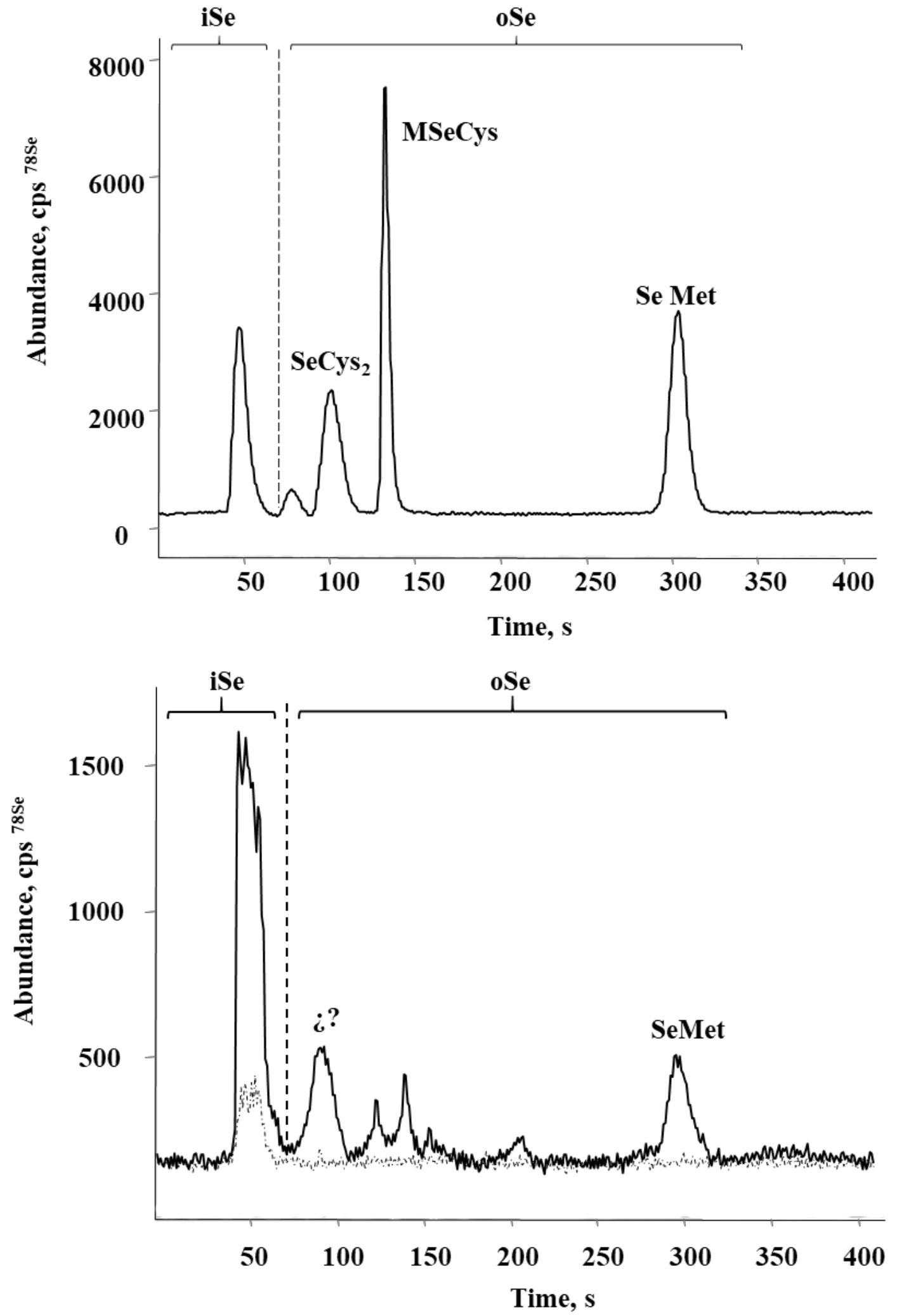

Fig. 4. Typical HPLC-ICP-MS chromatograms obtained to evaluate the percentage of iSe biotransformation: a) standard solution of Se(IV), (SeCys)2, SeMeCys and SeMet mix (10 $\mu$ g Se $\mathrm{L}^{-1}$ each); b) methanesulfonic acid hydrolyzates of alfalfa (control (---) and $0.25 \mathrm{mg} \mathrm{L}^{-1}$ (-). Elution regions of iSe and oSe are marked on each chromatogram. 


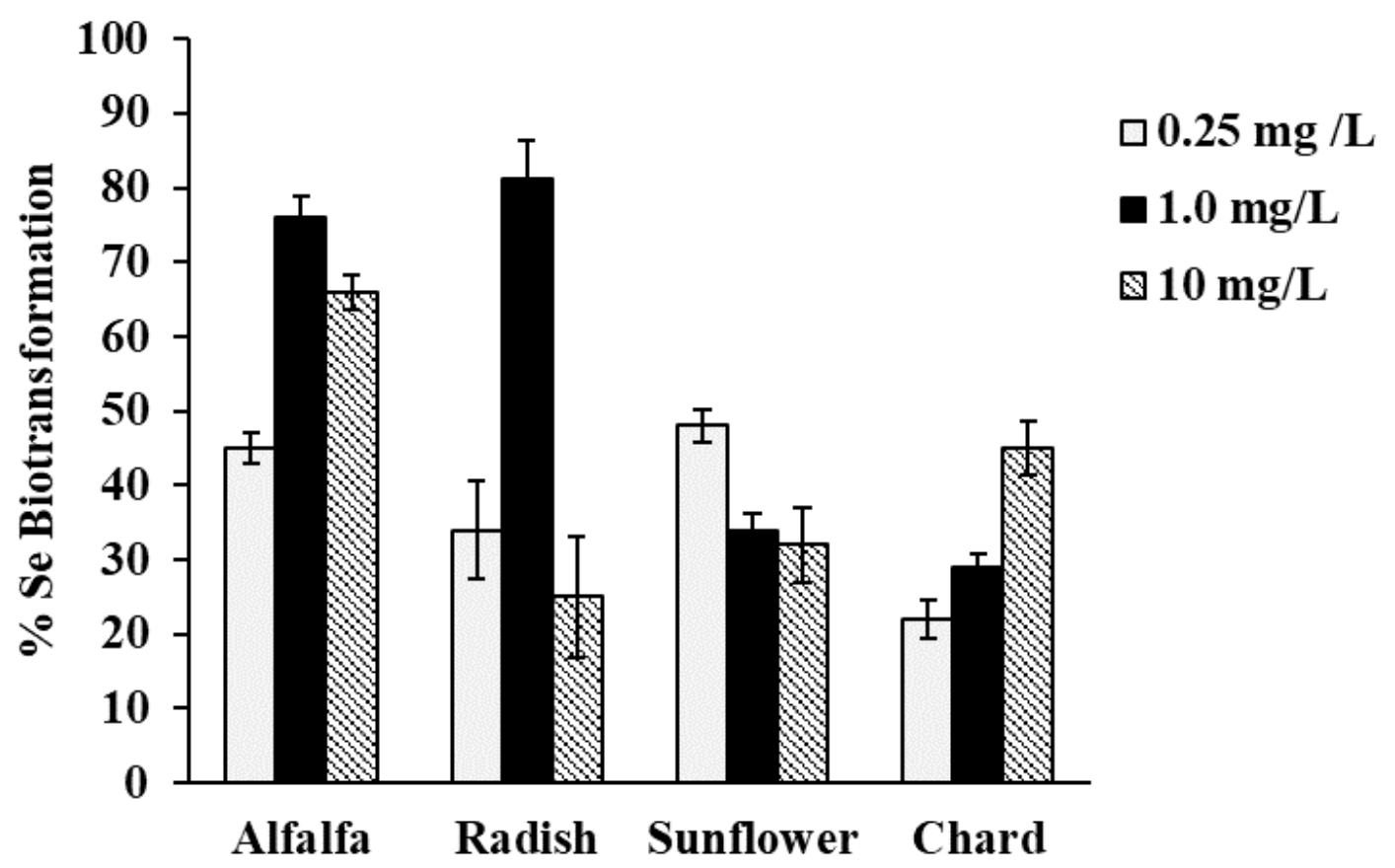

Fig. 5. Selenium biotransformation percentages obtained for four edible plants under different exposure conditions of Se(IV).

\section{Acknowledgements}

The financial support from the University of Guanajuato project 972/2016 and Secretary of Public Education project PRODEP UGTO-PTC-572.

\section{References}

1. Rayman, M. P. The Lancet 2000, 356, 233-241.

2. $\quad$ Kieliszek, M.; Błażejak, S. Nutrition 2013, 29, 713-718.

3. Navarro-Alarcon, M.; Cabrera-Vique, C. Science of The Total Environment 2008, 400, 115-141.

4. Valdiglesias, V.; Pasaro, E.; Mendez, J.; Laffon, B. Archives of toxicology 2010, 84, 337-351.

5. Liu, K.; Zhao, Y.; Chen, F.; Gu, Z.; Bu, G. European Food Research and Technology 2012, 234, 61-68.

6. $\quad$ Fairweather-Tait, S. J.; Bao, Y.; Broadley, M. R.; Collings, R.; Ford, D.; Hesketh, J. E.; Hurst, R. Antioxidants \& redox signaling 2011, 14, 1337-1383.

7. Thomson, C. D. The Analyst 1998, 123, 827-831.

8. Pyrzynska, K. Food Chemistry 2009, 114, 1183-1191.

9. Yáñez Barrientes, E.; Rodríguez Flores, C.; Wrobel, K.; Wrobel, K. Journal of the Mexican Chemical Society 2012, 56, 03-09.

10. Elguera, J. C. T.; Barrientos, E. Y.; Wrobel, K.; Wrobel, K. Acta Physiologiae Plantarum 2013, 35, 431-441.

11. Salt, D. E. Metallomics 2013, 5, 1088-1089.

12. Mounicou, S.; Szpunar, J.; Lobinski, R. Chemical Society Reviews 2009, 38, 1119-1138.

13. Arruda, M.; Azevedo, R. Annals of Applied Biology 2009, 155, 301-307.

14. López-Barea, J.; Gómez-Ariza, J. L. Proteomics 2006, 6. 
15. Wróbel, K.; Wróbel, K.; Kannamkumarath, S. S.; Caruso, J. A.; Wysocka, I. A.; Bulska, E.; Świątek, J.; Wierzbicka, M. Food Chemistry 2004, 86, 617-623.

16. Ellis, D. R.; Salt, D. E. Current opinion in plant biology 2003, 6, 273-279.

17. Lintschinger, J.; Fuchs, N.; Moser, J.; Kuehnelt, D.; Goessler, W. Journal of Agricultural and Food Chemistry 2000, 48, 5362-5368.

18. Elless, M. P.; Blaylock, M. J.; Huang, J. W.; Gussman, C. D. Food Chemistry 2000, 71, 181-188.

19. Waheed, S.; Rahman, S.; Siddique, N. Applied Radiation and Isotopes 2014, 89, 134-140.

20. Sierpina, V. S.; Devries, S.; Prasad, A.; Eisenberg, D.; McKee, J. M.; Kreitzer, M. J. EXPLORE: The Journal of Science and Healing 2013, 9, 192-195.

21. Schiavon, M.; Berto, C.; Malagoli, M.; Trentin, A.; Sambo, P.; Dall'Acqua, S.; Pilon-Smits, E. A. H. Frontiers in Plant Science 2016, 7, 1371.

22. Pedrero, Z.; Madrid, Y.; Camara, C. J Agric Food Chem 2006, 54, 2412-2417.

23. Hall, J. A.; Bobe, G.; Hunter, J. K.; Vorachek, W. R.; Stewart, W. C.; Vanegas, J. A.; Estill, C. T.; Mosher, W. D.; Pirelli, G. J. PLoS ONE 2013, 8, e58188.

24. Khattak, R. A.; Page, A. L.; Parker, D. R.; Bakhtar, D. Journal of Environmental Quality 1991, 20, 165-168.

25. Bierla, K.; Flis-Borsuk, A.; Suchocki, P.; Szpunar, J.; Lobinski, R. J Agric Food Chem 2016, 64, 4975-4981.

26. Garousi, F.; Veres, S.; Kovacs, B. Bulletin of environmental contamination and toxicology 2016, 97, 709-713.

27. Hernández-Castro, E.; Trejo-Téllez, L. I.; Gómez-Merino, F. C.; Rodríguez-Mendoza, M. N.; Sánchez-García, P.; Robledo-Paz, A. Journal of soil science and plant nutrition 2015, 15, 694710 .

28. Criollo, H.; García, J. Revista Colombiana de Ciencias Hortícolas 2011, 3, 210-222.

29. Gómez-Álvarez, R.; Lázaro-Jerónimo, G.; León-Nájera, J. Universidad y ciencia 2008, 24, 11-20.

30. Britannica, T. E. o. E.; Encyclopædia Britannica, inc.: Encyclopædia Britannica.

31. Uden, P. C.; Bird, S. M.; Kotrebai, M.; Nolibos, P.; Tyson, J. F.; Block, E.; Denoyer, E. Fresenius' Journal of Analytical Chemistry 1998, 362, 447-456.

32. Zarain, R. M. 2003.

33. Tenesaca, Q., 2014.

34. Wrobel, K.; Kannamkumarath, S. S.; Wrobel, K.; Caruso, J. A. Analytical \& Bioanalytical Chemistry 2003, 375, 133-138.

35. White, P. J.; Broadley, M. R. Trends in Plant Science 2005, 10, 586-593.

36. Karley, A. J.; White, P. J. Current opinion in plant biology 2009, 12, 291-298.

37. White, P. J.; Broadley, M. R. Annals of Botany 2003, 92, 487-511.

38. Gupta, M.; Gupta, S. Frontiers in Plant Science 2017, 7.

39. Gergely, V.; Montes-Bayón, M.; Fodor, P.; Sanz-Medel, A. Journal of Agricultural and Food Chemistry 2006, 54, 4524-4530.

40. Yu, Y.; Zhang, S.; Wen, B.; Huang, H.; Luo, L. Biological trace element research 2011, 143, 1789-1798.

41. Ximénez-Embún, P.; Alonso, I.; Madrid-Albarrán, Y.; Cámara, C. Journal of Agricultural and Food Chemistry 2004, 52, 832-838. 